\title{
A RELAÇÃO MÃE-BEBÊ NO CONTEXTO DA DEPRESSÃO PÓS-PARTO: ESTUDO QUALITATIVO
}

\section{Bruna Rafaele Milhorini Greinert}

Psicóloga, Mestre em Promoção da Saúde. Docente do departamento de Psicologia do Centro Universitário de Maringá (UNICESUMAR), Brasil.

\section{Eliete dos Reis Carvalho}

Enfermeira. Mestre em promoção da saúde. Docente do colegiado de enfermagem da Faculdade de Educação, Ciências e Filosofia de Mandaguari. Instrutora da saúde do SENAC-PR, Brasil.

\section{Hellen Capel}

Psicóloga pelo Centro Universitário de Maringá (UNICESUMAR), Brasil.

\section{Andréa Grano Marques}

Psicóloga, Doutora em Pediatria pela Universidade Federal de São Paulo. Docente Titular do Curso de Psicologia e do Programa de Mestrado em Promoção da Saúde do Centro Universitário de Maringá (UNICESUMAR). Bolsista do Programa de Produtividade em Pesquisa do Instituto Cesumar de Ciência, Tecnologia e Inovação (ICETI), Brasil.

\section{Rute Grossi Milani}

Docente Titular no Departamento de Psicologia e nos Programas de Mestrado em Promoção da Saúde e Tecnologias Limpas do Centro Universitário de Maringá (UNICESUMAR). Bolsista do Programa de Produtividade em Pesquisa do Instituto Cesumar de Ciência, Tecnologia e Inovação (ICETI), Brasil.
Autor correspondente:

Bruna Rafaele Milhorini Greinert

E-mail: brunamilhorini@hotmail.com
RESUMO: O objetivo deste estudo foi analisar como a sintomatologia depressiva em mulheres no período pós-parto influencia na relação mãe-bebê. Trata-se de uma pesquisa qualitativa, em que foram entrevistadas seis mães com idade entre 20 e 38 anos, atendidas em uma Unidade Básica de Saúde e que apresentaram sintomas depressivos no período pós-parto. Para a coleta de dados, utilizou-se a entrevista semiestruturada. Os resultados obtidos, a partir da análise de conteúdo, possibilitaram a compreensão de que os sintomas depressivos maternos afetam a relação mãe-bebê e a identificação de três categorias: a ambivalência afetiva na díade, a dificuldade materna na amamentação e a instabilidade no sono do bebê. Conclui-se que a mulher no período gravídico-puerperal necessita de apoio e suporte psicológico, a fim de reconhecer, prevenir e intervir sobre os fatores que interferem na sua saúde mental e promover o desenvolvimento saudável da relação mãe-bebê.

PALAVRAS-CHAVE: Maternidade; Saúde Mental; Saúde Materno-infantil.

\section{MOTHER-INFANT RELATIONSHIP WITHIN THE CONTEXT OF POST-PARTUM DEPRESSION: A QUANTITATIVE ANALYSIS}

\begin{abstract}
Current study analyzes how depressive symptomology in females during the post-partum period affects the mother-infant behavior. Qualitative research comprised interviews with six mothers, aged between 20 and 38 years, attended to at a Basic Health Unit, and who exhibited symptoms of depression during the after-birth period. The half-structured interview was employed for data collection. Results from content analysis revealed that mother's depression symptoms affected the mother-child relationship within three categories: affective ambivalence during dyade, mother's difficulties in breast feeding and instability in the infant's sleep. During the pregnancy-puerperal period, the mother has to be psychologically supported to acknowledge, prevent and interfere on factors that affect her mental health and promote the healthful development in mother-child relationship.
\end{abstract}

KEY WORDS: motherhood; mental health; mother-infant health.

\section{INTRODUÇÃO}

Todo recém-nascido necessita do acolhimento parental para que consiga sobreviver. A mãe, por meio de seus cuidados, é a principal 
responsável por acolher este novo ser e assim contribuir para seu desenvolvimento saudável ${ }^{1}$. Porém, em casos de depressão pós-parto (DPP) a função materna pode estar fragilizada, gerando dificuldades à mãe para exercer a maternagem ao recém-nascido. As mães depressivas, em sua maioria, sentem-se incapazes para realizar o cuidado materno e despreparadas para enfrentarem os desafios da maternidade ${ }^{2}$.

Em um estudo de base populacional, realizado no Brasil, constatou-se a alta prevalência da patologia no país, cerca de $26,3 \%$ das brasileiras apresentaram sintomas depressivos após o parto, ou seja, uma a cada quatro mães foram atingidas pela DPP. A pesquisa revelou importante problema de saúde pública, pois a sintomatologia depressiva da mãe está associada a maior vulnerabilidade social vivenciada pela mulher, como baixa condição financeira, antecedentes de transtorno mental e hábitos não saudáveis ${ }^{3}$.

No período gravídico-puerperal a mulher vivencia profundas transformações fisiológicas que interferem em sua produção hormonal e acarretam visíveis modificações corporais. Associado às alterações biológicas, a mulher pode apresentar dúvidas, angústias, medos e receios relacionados ao nascimento de um filho e à sua capacidade de cuidar de um bebê $\hat{e}^{2}$.

Os impactos da depressão pós-parto vão além do mundo interno da mãe e podem repercutir no vínculo afetivo que permeia a díade. Pelo fato do recém-nascido ser totalmente dependente, a relação que este estabelece com a figura materna configura-se como primordial para seu desenvolvimento. Portanto, é necessário entender de que forma a depressão pós-parto pode exercer influência na relação mãe-bebê.

Uma puérpera que apresenta depressão pós-parto pode manifestar atitudes variadas que irão permear sua relação com o filho, como maior hostilidade, rejeição, negligência e agressividade, bem como menor afetividade e maior ansiedade nos cuidados maternos. ${ }^{4} \mathrm{Um}$ estudo que analisou as interações entre mãe-bebê aos 18 meses de vida constatou que mães deprimidas tendem a apresentar altos níveis de estresse e de estabelecerem interações intrusivas com a criança. Para os autores, a depressão materna acarreta efeitos indesejáveis sobre a díade mãe-bebê e pode influenciar negativamente o desenvolvimento da crianças.
Pesquisas revelam que a depressão materna pode afetar a interação mãe-filho e gerar implicações para o desenvolvimento da criança, especialmente sobre a linguagem. De acordo com tais estudos, mães depressivas possuem menos capacidade para interagir, portanto conversam menos com os seus bebês e apresentam menos contato físico, o que pode acarretar desordens linguísticas, comportamentais, afetivas, cognitivas e sociais à criança, além de repercutir negativamente na díade mãe-bebêt $\hat{e}^{4-6}$.

Mulheres com depressão pós-parto também podem apresentar dificuldades quanto à amamentação; estudos revelaram a associação entre a depressão pós-parto e o abandono do aleitamento materno exclusivo ${ }^{7.8}$. Em uma pesquisa que cujo objetivo foi analisar a influência da saúde mental materna sobre o estado nutricional infantil em bebês no sexto mês de vida, descreveu que filhos de mães com transtornos mentais graves ou deprimidas apresentaram maior índice de deficiências nutricionais. Também foi constatado que filhos de mães com depressão obtiveram escores nutricionais inferiores ao de crianças com mães sem depressão. Tal estudo concluiu que a saúde mental da mãe está positivamente associada ao estado de desnutrição de crianças aos seis meses de vida?

A depressão materna também pode estar relacionada a alterações no sono do bebê. A associação entre as alterações no sono de bebês aos 12 meses de vida e a depressão pós-parto foi descrita na literatura. Segundo a pesquisa, a depressão pós-parto exerce influência direta nas alterações do sono infantil, como o despertar noturno e o sono agitado da criança. Os autores salientaram a necessidade de atenção à saúde mental das mães, a fim de propor intervenções que visem a prevenção de agravos e danos para o desenvolvimento infantil ${ }^{10}$.

Dentre as principais teorias que abordam a saúde mental materna e sua associação com o desenvolvimento infantil, destaca-se a teoria winnicottiana. De acordo com Winnicott, mães que apresentam depressão pós-parto possuem uma forma diferenciada para realizar os cuidados maternos quando comparadas às mães sem o transtorno. Pelo fato destas mulheres desenvolverem sintomas depressivos, a qualidade e a dedicação nos cuidados maternos para com a criança podem aumentar ou diminuir excessivamente. $\mathrm{O}$ autor discorre sobre a ne- 
cessidade da mãe em conhecer seu filho, pois ela é seu primeiro e mais importante contato com o mundo e também reconhece que a assistência materna é uma tarefa absorvente e contínua para a mãe $e^{11}$.

Em casos de depressão pós-parto, a maternagem encontra-se comprometida e pode acarretar consequências à relação mãe-bebê e na capacidade da mãe em proteger e estimular a criança, repercutindo negativamente sobre seu desenvolvimento. Mães acometidas por depressão materna podem apresentar dificuldades para identificarem as demandas do bebê. Tais mães não conseguem reconhecer no choro da criança seu real pedido, nem traduzir o verdadeiro significado de sua angústia ${ }^{12-13}$.

Considerando a literatura exposta, percebe-se que mulheres com depressão pós-parto encontram-se emocionalmente fragilizadas para realizar os cuidados maternos necessários à criança, tais dificuldades podem afetar a díade mãe-bebê. Dessa forma, o objetivo deste estudo foi analisar como a sintomatologia depressiva em mulheres no período pós-parto afeta a relação mãe-bebê.

\section{METODOLOGIA}

Trata-se de uma pesquisa qualitativa que possibilita a real compreensão do significado e da intencionalidade que permeia a sociedade, como os atos, as relações e as estruturas sociais humanas ${ }^{14}$.

\section{PARTICIPANTES}

Selecionaram-se seis mulheres com idade entre 20 e 38 anos, que apresentaram sintomas depressivos no período pós-parto, atendidas em Unidades Básicas de Saúde de um município da região Noroeste do Paraná. Adotou-se como critério de exclusão ser menor de 18 anos e ter recém-nascidos com má-formação congênita ou falecidos. As mulheres foram selecionadas mediante o encaminhamento realizado pelo profissional de enfermagem responsável pela UBS. As dificuldades de entrar em contato com essas mães foram significativas, pois se trata de um tema pessoal e pouco discutido entre a população, o que levou algumas mães a recusarem participar.

\section{INSTRUMENTOS}

Utilizou-se como instrumento de pesquisa um roteiro de entrevista semiestruturada; buscou-se o entendimento dos sintomas apresentados durante a depressão e como a doença afetou a relação da mãe com seu filho.

\section{PROCEDIMENTO DE COLETA E ANÁLISE DOS DADOS}

Primeiramente, foi realizado o contato com as mães a fim de esclarecer os objetivos da pesquisa e obter o consentimento destas. Enfatizou-se o compromisso com o sigilo em relação aos dados obtidos por meio da entrevista e a liberdade das participantes para desistirem do estudo a qualquer momento, caso desejassem. O presente estudo foi realizado conforme autorização do Comitê de Ética em Pesquisa com Seres Humanos do Centro Universitário de Maringá, mediante parecer nº 307/2011.

As entrevistas ocorreram no domicílio e foram gravadas mediante a autorização das participantes. Posteriormente, efetuou-se a transcrição, categorização e análise. A análise dos dados foi realizada com base no método qualitativo, discutidos sob o enfoque da psicanálise winnicottiana e com base em estudos empíricos sobre o tema. O critério utilizado na pesquisa para sistematização, análise e discussão dos dados, foi a análise de conteúdo, a qual possibilita a compreensão dos "significados". Permite ao pesquisador o entendimento das representações que o indivíduo tem sobre sua realidade e a interpretação que faz dos significados a sua volta ${ }^{15}$.

\section{RESULTADOS E DISCUSSÃO}

Mediante a análise de conteúdo das entrevistas derivaram-se três categorias apresentadas a seguir: ambivalência afetiva na díade, dificuldades materna na amamentação e instabilidade no sono. O perfil das entrevistadas referente à idade, estado civil e duração dos sintomas é apresentado na Tabela 1 . 
Tabela 1. Caracterização das mulheres entrevistadas, especificando idade, estado civil e tempo de duração dos sintomas depressivos após o parto

\begin{tabular}{c|c|c|c}
\hline Entrevistadas & Idade & Estado civil & $\begin{array}{c}\text { Tempo de duração } \\
\text { dos sintomas }\end{array}$ \\
\hline E1 & 20 & Solteira & 3 meses \\
\hline E2 & 20 & Casada & 4 meses \\
\hline E3 & 22 & Solteira & 4 meses \\
\hline E4 & 23 & Casada & 4 meses \\
\hline E5 & 35 & Casada & 4 meses \\
\hline E6 & 38 & Casada & 5 meses \\
\hline
\end{tabular}

Fonte: dados da pesquisa

\section{AMBIVALÊNCIA AFETIVA NA DÍADE}

Mulheres com depressão pós-parto podem apresentar sentimentos variados em relação à criança e que irão influenciar sua relação com o filho, tais como rejeição, negligência, agressividade e maior hostilidade. Essas mães podem apresentar maior ansiedade para realizar os cuidados maternos e menos afetividade para com o bebêt ${ }^{4}$. Com base nos relatos das mulheres entrevistadas, pôde-se verificar a ambivalência afetiva presente na díade mãe-criança.Tais fatos foram constatados em nosso estudo, pois as mães relataram sentimentos aversivos em relação à criança:

"Eu não cuidava dela, não gostava de ficar perto". (E4)

"Raiva, era isso que eu sentia, eu tinha raiva, não queria ficar perto, na gravidez me saiu muita estria sabe, aí eu me olhava no espelho, estava gorda e com aquelas estrias, eu chorava e colocava a culpa nele, eu tinha raiva". (E1)

A base para a constituição psíquica do ser humano é decorrente dos primórdios da díade, pois a criança necessita da presença afetiva e constante do outro, sendo a mãe a principal responsável por acolher seu modo singular e espontâneo de vir ao mundo. ${ }^{16}$ A maternidade é considerada um momento que requer da mulher intensas adaptações de sua vida e o aprendizado de novos cuidados dispensados a um bebê, tais fatores exigem da mãe maturidade emocional para lidar com as mudanças advindas deste período. ${ }^{11}$ Nos relatos analisados, nota-se a instabilidade afetiva por meio da raiva e da negligência aos cuidados maternos, sinalizando que estas mães possivelmente estão com dificuldades para enfrentar os desafios desta nova fase e ofertar ao filho o acolhimento genuíno, pela sua inconstância afetiva.

Mães com depressão pós-parto se deparam com duas facetas da emoção, a alegria da chegada do bebê e a cruel tristeza decorrente desse fato. Os relatos das participantes da pesquisa sugerem que mães com depressão pós-parto sofrem com a contradição entre o comportamento acolhedor e protetor esperado socialmente e os sintomas provocados pela patologia, que se manifestam por meio de raiva, alta irritabilidade e rejeição ao filho. Mães depressivas apresentam menor capacidade de interação com a criança e estabelecem menos contato físico com seus filhos ${ }^{6-17}$. Tais considerações são concordantes com os achados em nosso estudo, conforme os relatos apresentados a seguir:

\footnotetext{
"Eu gostava dela, mas eu não tinha paciência, se ela chorava eu não queria olhar, eu queria ela longe, ali sabe". (E2)

"Eu tinha desprezo sabe, não tenho vergonha de falar. Hoje eu amo ela, ela é tudo na minha vida, mas antes eu não queria ela, não amava, não conseguia. Parece que ela veio pra me atrapalhar". (E3)
}

Mães com depressão pós-parto possuem dificuldades para identificar as demandas do filho e não reconhecem o real significado do choro da criança. ${ }^{12}$ Nota-se nos relatados apresentados que a mãe, frente ao choro da criança, via-se desestabilizada e sem condições para dar significado à angústia do filho e nem identificar sua real necessidade. O desprezo e a negligência demonstrados pelos relatos podem ser vistos como uma forma das mães em se defender da angústia que permeia sua relação com o bebê, pois não possuem condições para oferecer cuidado à criança, tão pouco continência materna.

As mães entrevistadas apresentaram dificuldade em oferecer apoio e segurança a seus bebês, visto que, muitas sentiam repulsa e raiva da criança, e culpavam os filhos pelas dificuldades geradas pela gravidez. A ambivalência afetiva demonstrada pela mãe em relação à criança é, na realidade, reflexo da instabilidade emocional que permeia o mundo materno. 


\section{DIFICULDADES MATERNAS NA AMAMENTAÇÃO}

A amamentação é um processo que ultrapassa a finalidade da nutrição, pois além de suprir as necessidades fisiológicas nas quais garante a sobrevivência do recém-nascido, também abrange os laços afetivos da díade, visto que é o primeiro contato do bebê com o mundo externo, sendo, desta forma, indispensável na constituição da relação mãe-filho ${ }^{18}$. Em nosso estudo, as mães tiveram dificuldades para amamentar:

"A amamentação dela foi só por dias, depois eu não tinha mais leite. Então, eu tive uma alergia, aí o leite secou. Ela queria "mamar", mas eu não conseguia dar." (E2)

"Ela não pegava o peito, porque não tinha bico, ela nem pegou direito." (E5)

A amamentação é o início do processo da mulher no enfrentamento da sua nova experiência, a de ser mãe. Este momento pode começar com frustração e medo pela incapacidade de suprir as necessidades básicas do filho, o que gera um estado de nervosismo e estresse na mulher ${ }^{19}$. Os achados do presente estudo evidenciam que as mães com dificuldades no processo de amamentação, visto o estado depressivo, apresentavam-se bastante angustiadas e frustradas por não conseguirem amamentar o bebê. Esse fato é confirmado pelos relatos apresentados a seguir:

"Quando eu via que não dava certo, que ela não "pegava", eu chamava a minha mãe, ficava desesperada, começava a chorar e chamava minha mãe, porque eu não queria fazer nada, eu queria que a bebê dormisse o dia inteiro. Na hora que ela acordava pra mim era horrível, eu pensava: Ela vai querer "mamar" agora, aí eu ficava nervosa e começava a chorar de nervoso, de tudo". (E3)

"Eu era paciente, às vezes, quando eu estava bem, mas às vezes eu queria ficar sozinha, não queria ficar perto da bebê. Quando ela se recusava a "mamar" e eu estava bem, eu era paciente, esperava passar e tentava de novo, quando eu 'tava' mal eu nem chegava perto, deixava chorar". (E4)
Quando o filho chora, além da perda do equilíbrio emocional, a mãe pode não se sentir capaz de cuidar do seu bebê, o que gera uma sensação de incapacidade diante de outras mulheres que conseguem atender com mais facilidade as necessidades de seus filhos. Essa decepção consigo mesma de não conseguir desempenhar a contento o papel de mãe, vai se agravando e se tornando mais evidende com o passar dos dias ${ }^{19}$. O desinteresse em amamentar foi identificado nas entrevistadas, as quais relataram o aumento da irritabilidade e medo no momento da amamentação, o que interferia para certo afastamento em relação à criança.

"Eu não queria, não gostava, me sentia muito mal". (E1)

"Eu não "dei de mamar", dei cinco dias na verdade, mas parei, eu tinha medo, não queria pegar no colo [..] eu não queria, não conseguia mesmo". (E6)

"Ela não mamou direito, eu não queria, sabe $[. .$.$] aí eu comecei a tomar o$ remédio, tive que parar de dar". (E4)

Em relação ao abandono do aleitamento materno, os sintomas de DPP estão caracterizados como uma variável relacionada ao desmane precoce. Em uma pesquisa que buscou avaliar os determinantes do abandono do aleitamento materno exclusivo, constatou-se que a depressão pós-parto e o parto traumático são as únicas variáveis para o abandono da amamentação exclusiva. Desta forma, pode-se inferir que o estado emocional da mulher é fundamental para um bom desempenho do aleitamento ${ }^{7}$.

A amamentação ao recém-nascido está relacionada com a capacidade da mãe em adaptar-se às necessidades da criança. Nos casos em que o bebê mostra-se incapaz de aceitar o seio materno não está associado a qualquer incapacidade inata sua, mas à dificuldade da mãe em proporcionar ao filho gratificação e satisfação por meio da amamentação. O prazer e a excitação do bebê, provenientes da experiência de ser amamentado, ficam contaminados pela angústia ou depressão materna ${ }^{11}$.

O aleitamento materno é um processo que envolve as condições fisiológicas e psicológicas da mulher, visto que as mães se encontram naturalmente em um momento de fragilidade emocional. É notavel que sintomas depressivos podem interferir no processo de amamenta- 
ção. Por se sentirem inseguras, com medo ou até por falta de apoio e orientação, algumas mães deixam de amamentar seus filhos precocemente, o que pode gerar sentimento de frustração em relação ao exercício da maternidade.

A fragilidade materna é um importante aspecto a ser considerado, pois devido à sintomatologia depressiva a mãe pode estar emocionalmente instável e apresentar dificuldades para exercer os cuidados primários à criança. Ao demonstrar fragilidade em relação à amamentação pode não ser compreendida pelos profissionais de saúde e familiares, já que este é um comportamento materno esperado culturalmente. Reconhecer a fragilidade materna é de extrema importância para que seja possível ofertar não somente apoio à criança, mas também à mãe, acolhendo suas angústias e frustrações. Neste sentido, é fundamental que os profissionais de saúde envolvidos no processo gravídico puerperal ofereçam suporte emocional e escuta diferenciada acerca das dificuldades presentes na amamentação, a fim de fortalecer a díade mãe-bebê.

\section{INSTABILIDADE NO SONO}

Em relação às alterações no sono do bebê, observaram-se certas dificuldades relatadas pelas mães que participaram deste estudo, tais como o sono leve, agitado e de curta duração. Um dos fatores associados às alterações no sono de bebês seria a presença de sintomas depressivos maternos. O despertar noturno e o sono agitado da criança são influenciados pela patologia das mães ${ }^{10}$. Esse fato foi constado em nosso estudo mediante os relatos apresentados a seguir:

"Ela sempre teve o sono leve, tem até hoje, ela sempre foi de dormir tarde e acordar cedo. Assim, durante o dia ela nunca foi de dormir, dormia tarde, umas 23:30 e acordava várias vezes, não era um sono profundo, era leve, qualquer coisa acordava, ela não trocava o dia pela noite, só tinha o sono muito levinho, era difícil". (E6)

"Ah, ela não dormia bem à noite não, tinha o sono muito leve, acordava muito, às vezes nem conseguia pegar no sono". (E2)

"Sempre foi bem ruim, ela ía dormir tarde da madrugada e acordava cedinho, o sono era continuo, mas curto". (E5)
Em crianças com até dois anos de vida, o sono é o responsável por revelar a qualidade da interação existente entre pais e filhos. A mãe, por sua vez, é vista como a guardiã do sono de seu filho ${ }^{20}$. Nesta perspectiva, podese inferir que as mães entrevistadas demonstram dificuldades para exercer seu papel como protetora do sono da criança, e tais alterações apresentadas pelos bebês indicam falhas na díade.

As dificuldades de sono de um bebê estão relacionadas à sua separação da mãe, o que requer muita tolerância e serenidade por parte do cuidador. Quando o ambiente onde a criança está inserida é incapaz de tolerar suas angústias, as dificuldades do sono irão persistir, pois estão ligadas às condições emocionais de seu cuidador $^{21}$. Mediante tais considerações, percebe-se que as mães de nosso estudo por estarem deprimidas e emocionalmente vulneráveis apresentaram dificuldades para conter suas próprias angústias advindas da maternidade e, consequentemente, não possibilitaram à criança condições favoráveis para que ocorra a separação gradativa. A instabilidade no sono simboliza as dificuldades que o bebê tem para encontrar em sua mãe uma figura que lhe proporcione segurança.

Com base nestas considerações, pode-se inferir que as mães demonstraram dificuldades para acolher e conter a angústia do filho. Tais fatores estão interligados às alterações no sono da criança, uma vez que a mãe emocionalmente fragilizada, pode estar menos fortalecida para suportar e atender as demandas de cuidado do seu bebê.

\section{CONCLUSÃO}

Este estudo visou analisar como a sintomatologia depressiva em mulheres no período pós-parto afeta a relação mãe-bebê. A partir dos dados coletados, pôde-se constatar que a presença de sintomas depressivos maternos exerce influência sobre a relação mãe-bebê, especialmente nos três a cinco primeiros meses após o parto, pois nesse período as mães depressivas apresentaram dificuldade para desempenhar suas funções maternas, visto que manifestaram sentimentos de desprezo, raiva, culpa e rejeição pela criança. Os resultados obtidos com a pes- 
quisa possibilitaram a compreensão de que os sintomas depressivos maternos interferem na relação mãe-criança, pois se verificou a ambivalência afetiva na díade, dificuldade no aleitamento materno e instabilidade no sono do bebê.

A depressão pós-parto, por se tratar de um tema pessoal e pouco discutido entre a população, deve ser abordado com cautela. No presente estudo, salientam-se as dificuldades em realizar o contato com as participantes, pois se trata de um tema delicado e pessoal. A maior parte das entrevistadas se emocionou durante o relato dos momentos vividos, especialmente ao se tratar da rejeição e agressividade manifestadas contra o bebê, e da dualidade de sentimentos. Outro aspecto importante constatado refere-se à precariedade no diagnóstico da depressão pós -parto, muitas vezes as mudanças do comportamento da mãe são percebidas, mas ainda falta esclarecimento acerca da patologia, o que dificulta a procura por tratamento. Os resultados deste estudo permitem concluir que a mulher no perído gravídico-puerperal necessita de apoio e suporte psicológico, na tentativa de reconhecer, prevenir e intervir sobre os fatores que podem afetar a saúde mental materna e promover o desenvolvimento saudável da díade mãe-bebê.

\section{REFERÊNCIAS}

1. Goretti ACS, Almeida SFC, Legnani VN. A relação mãe -bebê na estimulação precoce: um olhar psicanalítico. Estilos da Clinica, 2014;19(3):414-35.

2. Greinert, BRM, Milani RG. Depressão pós-parto: uma compreensão psicossocial. Psicol. teor. $e$ prát. 2015;17(1):26-36.

3. Theme MMF, Ayers S, Gama SGN, Leal MC. Factors associated with postpartum depressive symptomatology in Brazil: The Birth in Brazil National Research Study, 2011/2012. J Affect Disord. 2016;194:159-67.

4. Servilha B, Bussad VSR. Interação Mãe-Criança e Desenvolvimento da Linguagem: A Influência da Depressão Pós-Parto. Psico. 2015;46(1):101-109.

5. Alvarenga P, Palma ES. Indicadores de Depressão Materna e a Interação Mãe-Criança aos 18 Meses de Vida. Psico, 2013;44(3):402-10.
6. Carlesso JPP, Souza APR. Dialogia mãe-filho em contextos de depressão materna: revisão de literatura. Rev CEFAC. 2011;13(6):1119-26.

7. Machado MCM, Assis KF, Oliveira FCC, Ribeiro AQ, Araújo RMA, Cury AF, et al. Determinantes do abandono do aleitamento materno exclusivo: fatores psicossociais. Rev Saúde Pública. 2014;48(6):985-94.

8. Matos JM, Silva VLQ, Rosa WAG, Oliveira ISB. Análise da depressão pós-parto no período puerperal e sua relação com o aleitamento materno. Rev Iniciação Científica da Libertas. 2013;3(1):50-66.

9. Hassan BK, Werneck GL, Hasselmann MH. Saúde mental materna e estado nutricional de crianças aos seis meses de vida. Rev Saúde Pública. 2016;50(7):1-9.

10. Lopes ER, Jansen K, Quevedo LA, Vanila RG, Silva RA, Pinheiro RT. Depressão pós-parto e alterações de sono aos 12 meses em bebês nascidos na zona urbana da cidade de Pelotas/RS. J Bras Psiquiatr. 2010;59(2):88-93.

11. Winnicott, DW. A criança e o seu mundo. Rio de Janeiro: JC; 1982.

12. Carlesso JPP, Souza APR, Moraes AB. Análise da relação entre depressão materna e indicadores clínicos de risco para o desenvolvimento infantil. Rev CEFAC. 2014;16(2):500-10.

13. Fernandes FC, Cotrin JTD. Depressão pós-parto e suas implicações no desenvolvimento infantil. Rev Panorâmica On-Line. 2013;14:15-34.

14. Minayo, MC. S. O desafio do conhecimento: pesquisa qualitativa em saúde. São Paulo: Hucitec; 2004.

15. Bardin, L. Análise de Conteúdo. Lisboa: Edições 70; 1997.

16. Cambuí HÁ, Neme CMB, Abrão JLF. A constituição subjetiva e saúde mental: contribuições winnicottianas. Ágora (Rio de Janeiro), 2016;19(1):131-45.

17. Cunha AB, Riscken JX, Lima P, Gil S, Cyrino LA. A Importância do acompanhamento psicológico durante a gestação em relação aos aspectos que podem preve- 
nir a depressão pós-parto. Saúde e Pesqui. 2012;5(3): 579-86.

18. Ministério da Saúde (BR). Secretaria de Atenção à saúde. Departamento de Atenção Básica. Saúde da criança: nutrição infantil: aleitamento materno e alimentação complementar. Brasília: Ministério da Saúde; 2009.

19. Barbosa MARS, Angelo M. Vivências e significados da depressão pós-parto de mulheres no contexto da família. Enfermería Global. 2016;15(2):256-79.

20. Mazet P, Braconnier A. O sono das crianças e seus problemas. Rio de Janeiro: Bertrand Brasil; 1993.

21. Soifer R. Psiquiatria infantil operativa. Porto Alegre: Artes Médicas; 1992.

Recebido em: 10/06/2017

Aceito em: 22/02/18 